Eleanor L. S. Leavens, PhD; John R. Freedy, MD, PhD

University of Kansas School of Medicine, Kansas City (Dr. Leavens); Medical University of South Carolina, Charleston (Dr. Freedy)

Deleavens@kumc.edu

The authors reported no potential conflict of interest relevant to this article.

The author (ELSL) was supported by a CTSA grant from NCATS awarded to the University of Kansas for Frontiers: University of Kansas Clinical and Translational Science Institute \# 5TL1TR002368. The contents are solely the responsibility of the authors and do not necessarily represent the official views of the NIH or NCATS

doi: $10.12788 / \mathrm{jfp} .0254$

\section{Youth e-cigarette use: Assessing for, and halting, the hidden habit}

\author{
Using a checklist to establish patients' level of \\ dependence and combining behavioral therapy with \\ nicotine replacement products can help users to quit.
}

\section{$>$ THE CASE}

Joe, an 18-year-old, has been your patient for many years and has an uncomplicated medical history. He presents for his preparticipation sports examination for the upcoming high school baseball season. Joe's mother, who arrives at the office with him, tells you she's worried because she found an e-cigarette in his backpack last week. Joe says that many of the kids at his school vape and he tried it a while back and now vapes "a lot."

After talking further with Joe, you realize that he is vaping every day, using a $5 \%$ nicotine pod. Based on previous consults with the behavioral health counselor in your clinic, you know that this level of vaping is about the same as smoking 1 pack of cigarettes per day in terms of nicotine exposure. Joe states that he often vapes in the bathroom at school because he cannot concentrate in class if he doesn't vape. He also reports that he had previously used 1 pod per week but had recently started vaping more to help with his cravings.

You assess his withdrawal symptoms and learn that he feels on edge when he is not able to vape and that he vapes heavily before going into school because he knows he will not be able to vape again until his third passing period.

\section{O HOW WOULD YOU PROCEED WITH THIS PATIENT?}

$\mathrm{E}$ lectronic cigarettes (e-cigarettes; also called "vapes") are electronic nicotine delivery systems that heat and aerosolize e-liquid or "e-juice" that is inhaled by the user. The e-liquid is made up primarily of propylene glycol, vegetable glycerin, and flavorings, and often includes nicotine. Nicotine levels in e-cigarettes can range from $0 \mathrm{mg} / \mathrm{mL}$ to $60 \mathrm{mg} / \mathrm{mL}$ (regular cigarettes contain $\sim 12 \mathrm{mg}$ of nicotine). The nicotine level of the pod available from e-cigarette company JUUL (50 $\mathrm{mg} / \mathrm{mL}$ e-liquid) is equivalent to about 1 pack of cigarettes. ${ }^{1}$ E-cigarette devices are relatively affordable; popular brands cost $\$ 10$ to $\$ 20$, while the replacement pods or eliquid are typically about $\$ 4$ each.

The e-cigarette market is quickly evolving and diversifying. Originally, e-cigarettes looked similar to cigarettes (cig-a-likes) but did not efficiently deliver nicotine to the user. ${ }^{2}$ E-cigarettes have evolved and some now deliver cigarette-like levels of nicotine to the user. $^{3,4}$ Youth and young adults primarily use pod-mod e-cigarettes, which have a sleek design and produce less vapor than older e-cigarettes, making them easier to conceal. 
They can look like a USB flash-drive or have a teardrop shape. Pod-mod e-cigarettes dominate the current market, led by companies such as JUUL, NJOY, and Vuse. ${ }^{5}$

- E-cigarette use is proliferating in the United States, particularly among young people and facilitated by the introduction of pod-based e-cigarettes in appealing flavors. ${ }^{6,7}$ While rates of current e-cigarette use by US adults is around $5.5 \%,{ }^{8}$ recent data show that $32.7 \%$ of US high school students say they've used an e-cigarette in the past 30 days. ${ }^{9}$

A double-edged sword. E-cigarettes are less harmful than traditional cigarettes in the short term and likely benefit adult smokers who completely substitute e-cigarettes for their tobacco cigarettes. ${ }^{10}$ In randomized trials of adult smokers, e-cigarette use resulted in moderate combustible-cigarette cessation rates that rival or exceed rates achieved with traditional nicotine replacement therapy (NRT) ${ }^{11-13}$ However, most e-cigarettes contain addictive nicotine, can facilitate transitions to more harmful forms of tobacco use, ${ }^{10,14,15}$ and have unknown long-term health effects. Therefore, youth, young adults, and those who are otherwise tobacco naïve should not initiate e-cigarette use.

Moreover, cases of e-cigarette or vaping product use-associated lung injury (EVALI) a disease linked to vaping that causes cough, fever, shortness of breath, and death-were first identified in August 2019 and peaked in September 2019 before new cases decreased dramatically through January $2020 .{ }^{16}$ Since the initial cases of EVALI arose, product testing has shown that tetrahydrocannabinol (THC) and vitamin $\mathrm{E}$ acetate are the main ingredients linked to EVALI cases. ${ }^{17}$ For this reason, the Centers for Disease Control and Prevention and others strongly recommend against use of THC-containing e-cigarettes. ${ }^{18}$

Given the high rates of e-cigarette use among youth and young adults and its potential health harms, it is critical to inquire about e-cigarette use at primary care visits, and, as appropriate, to assess frequency and quantity of use. Patients who require intervention will be more likely to succeed in quitting if they are connected with behavioral health counseling and prescribed medication. This article offers evidence-based guidance to assess and advise teens and young adults regarding the potential health impact of e-cigarettes.

\section{A NEW ICD-10-CM CODE AND A BRIEF ASSESSMENT TOOL} According to the Diagnostic and Statistical Manual of Mental Disorders, 5th Edition $(D S M-5)^{19}$ and the International Classification of Diseases, 10th Revision (ICD-10-CM), ${ }^{20}$ a tobacco use disorder is a problematic pattern of use leading to clinically significant impairment or distress. Associated features and behavioral markers of frequency and quantity include use within 30 minutes of waking, daily use, and increasing use. However, with youth, consider intervention for use of any nicotine or tobacco product, including e-cigarettes, regardless of whether it meets the threshold for diagnosis. ${ }^{21}$

The new code. Interestingly, prior to the April 2020 modification to ICD-10-CM codes, there was no code for e-cigarette use-related problems. However, the newly released code (U07.0) allows for billing for these services and serves to recognize the importance of screening, diagnosis, and treatment of e-cigarette use.

As with other tobacco use, assess ecigarette use patterns by asking questions about the frequency, duration, and quantity of use. Additionally, determine the level of nicotine in the e-liquid (discussed earlier) and evaluate whether the individual displays signs of physiologic dependence (eg, failed attempts to reduce or quit e-cigarette use, increased use, nicotine withdrawal symptoms).

A useful assessment tool. While e-cigarette use is not often included on current substance use screening measures, the above questions can be added to the end of measures such as the CRAFFT (Car-Relax-AloneForget-Family and Friends-Trouble) test. ${ }^{22}$ Additionally, if an adolescent reports vaping, the American Academy of Pediatrics (AAP) recommends using a brief screening tool such as the Hooked on Nicotine Checklist (HONC) to establish his or her level of dependence (TABLE 1). ${ }^{23}$

The HONC is ideal for a primary care settingbecause itisbriefandhas ahighlevel of sensitivity, minimizing false-negative reports ${ }^{24}$;

\section{$>$}

Data show that $32.7 \%$ of US high school students say they've used an e-cigarette in the past 30 days. 


\section{TABLE 1}

\section{The Hooked on Nicotine Checklist (HONC) ${ }^{23}$}

\begin{tabular}{|c|c|c|}
\hline Instructions: Please respond to each question by marking 1 box per row. & Yes & No \\
\hline \multicolumn{3}{|l|}{ 1. Have you ever tried to stop vaping, but couldn't? } \\
\hline \multicolumn{3}{|l|}{ 2. Do you vape now because it is really hard to quit? } \\
\hline \multicolumn{3}{|l|}{ 3. Have you ever felt like you were addicted to vaping? } \\
\hline \multicolumn{3}{|l|}{ 4. Do you ever have strong cravings to vape? } \\
\hline \multicolumn{3}{|l|}{ 5. Have you ever felt like you really needed to vape? } \\
\hline \multicolumn{3}{|c|}{ 6. Is it hard to keep from vaping in places where you are not supposed to, such as school? } \\
\hline \multicolumn{3}{|l|}{ When you tried to stop vaping ... (or when you haven't vaped for a while ...) } \\
\hline \multicolumn{3}{|l|}{ 7. did you find it hard to concentrate because you couldn't vape? } \\
\hline \multicolumn{3}{|l|}{ 8. did you feel more irritable because you couldn't vape? } \\
\hline \multicolumn{3}{|l|}{ 9. did you feel a strong need or urge to vape? } \\
\hline 10. did you feel nervous, restless, or anxious because you couldn't vape? & & \\
\hline
\end{tabular}

Note: This checklist has been adapted from its original version (which addressed cigarette smoking) to address individuals who vape e-cigarettes. To score the measure, total the number of "Yes" responses. Any score $>0$ indicates that the patient has lost some degree of autonomy over their e-cigarette use. Higher scores indicate higher level of dependence.

a patient's acknowledgement of any item indicates a loss of autonomy over nicotine. Establishing the level of nicotine dependence is particularly pertinent when making decisions regarding the course of treatment and whether to prescribe NRT (eg, nicotine patch, gum, lozenge). Alternatively, you can quickly assess level of dependence by determining the time to first e-cigarette use in the morning. Tobacco guidelines suggest that if time to first use is $>30$ minutes, the individual is "moderately dependent"; if time to first use is $<30$ minutes after waking, the individual is "severely dependent." ${ }^{25}$

\section{COMBINATION TREATMENT IS MOST SUCCESSFUL}

Studies have shown that the most effective treatment for tobacco cessation is pairing behavioral treatment with combination NRT (eg, nicotine gum + patch). ${ }^{25,26}$ The literature on e-cigarette cessation remains in its infancy, but techniques from traditional smoking cessation can be applied because the behaviors differ only in their mode of nicotine delivery.

IBehavioral treatment. There are several options for behavioral treatment for tobacco cessation-and thus, e-cigarette cessation. The first step will depend on the patient's level of motivation. If the patient is not yet ready to quit, consider using brief motivational interviewing. Once the patient is willing to engage in treatment, options include setting a mutually agreed upon quit date or planning for a reduction in the frequency and duration of vaping.

Referrals to the Quitline (800-QUIT-NOW) have long been standard practice and can be used to extend primary care treatment. ${ }^{25}$ Studies show that it is more effective to connect patients directly to the Quitline at their primary care appointment ${ }^{27}$ than asking them to call after the visit. ${ }^{28,29}$ We suggest providing direct assistance in the office to patients as they initiate treatment with the Quitline.

Finally, if the level of dependence is severe or the patient is not motivated to quit, connect them with a behavioral health provider in your clinic or with an outside therapist skilled in cognitive behavioral techniques related to tobacco cessation. Discuss with the patient that quitting nicotine use is difficult for many people and that the best option for success is the combination of counseling and medication. ${ }^{25}$

Nicotine replacement therapy for e-cigarette use. While over-the-counter 
TABLE 2

\section{Tobacco use billing codes ${ }^{35}$}

\begin{tabular}{l|l|l}
\hline Billing code & Description & Average reimbursement \\
\hline 99406 & Smoking/tobacco use cessation counseling, $>3$ minutes and up to 10 minutes & $\$ 15.70^{\text {a }}$ \\
\hline 99407 & Smoking/tobacco use cessation counseling, intensive, $>10$ minutes & $\$ 28.96^{\mathrm{a}}$ \\
\hline
\end{tabular}

average reimbursement indicates dollar amount as of 8/26/21.

NRT (nicotine gum, patches, lozenges) is approved by the US Food and Drug Administration only for sale to adults $\geq 18$ years, the AAP issued guidance on prescribing NRT for those $<18$ years who use e-cigarettes. ${ }^{30}$ While the AAP does not suggest a lower age limit for prescribing NRT, national data show that $<6 \%$ of middle schoolers report e-cigarette use and that e-cigarette use does not become common ( $20 \%$ current use) until high school. ${ }^{31}$ It is therefore unlikely that a child $<14$ years would require pharmacotherapy. On their fact sheet, the AAP includes the following guidance:

"Patients who are motivated to quit should use as much safe, FDA-approved NRT as needed to avoid smoking or vaping. When assessing a patient's current level of nicotine use, it may be helpful to understand that using one JUUL pod per day is equivalent to one pack of cigarettes per day .... Pediatricians and other healthcare providers should work with each patient to determine a starting dosage of NRT that is most likely to help them quit successfully. Dosing is based on the patient's level of nicotine dependence, which can be measured using a screening tool" $\left(\text { TABLE } 1^{23}\right)^{32}$

The AAP NRT dosing guidelines can be found at downloads.aap.org/RCE/NRT_and _Adolescents_Pediatrician_Guidance _factsheet.pdf. ${ }^{32}$ Of note, the dosing guidelines for adolescents are the same as those for adults and are based on level of use and dependence. Moreover, the clinician and patient should work together to choose the initial dose and the plan for weaning NRT over time.

\section{$>$ THE CASE}

Based on your conversation with Joe, you administer the HONC screening tool. He scores
9 out of 10, indicating significant loss of autonomy over nicotine. You consult with a behavioral health counselor, who believes that Joe would benefit from counseling and NRT. You discuss this treatment plan with Joe, who says he is ready to quit because he does not like feeling as if he depends on vaping. Your shared decision is to start the 21-mg patch and 4-mg gum with plans to step down from there.

Joe agrees to set a quit date in the following week. The behavioral health counselor then meets with Joe and they develop a quit plan, which is shared with you so you can follow up at the next visit. Joe also agrees to talk with his parents, who are unaware of his level of use and dependence. Everyone agrees on the quit plan, and a follow-up visit is scheduled.

At the follow-up visit 1 month later, Joe and his parents report that he has quit vaping but is still using the patch and gum. You instruct Joe to reduce his NRT use to the 14-mg patch and 2-mg gum and to stop using them over the next 2 to 3 weeks. Everyone is in agreement with the treatment plan. You also re-administer the HONC screening tool and see that Joe's score has reduced by 7 points to just 2 out of 10. You recommend that Joe continue to see the behavioral health counselor and follow up as needed. (A noted benefit of having a behavioral health counselor in your clinic is the opportunity for informal briefings on patient progress. ${ }^{33,34}$ )

Following each visit with Joe, you make sure to complete documentation on (1) tobacco/e-cigarette use assessment, (2) diagnoses, (3) discussion of benefits of quitting, (4) assessment of readiness to quit, (5) creation and support of a quit plan, and (6) connection with a behavioral health counselor and 
planned follow-up. (See TABLE $2^{35}$ for details on billing codes.)

CORRESPONDENCE

Eleanor L. S. Leavens, PhD, 3901 Rainbow Boulevard, Mail Stop 1008, Kansas City, KS 66160; eleavens@kumc.edu

\section{References}

1. Prochaska JJ, Vogel EA, Benowitz N. Nicotine delivery and cigarette equivalents from vaping a JUULpod. Tob Control. Published online March 24, 2021 doi: 10.1136/tobaccocontrol2020-056367

2. Rüther T, Hagedorn D, Schiela K, et al. Nicotine delivery efficiency of first-and second-generation e-cigarettes and its impact on relief of craving during the acute phase of use. Int J Hyg Environ Health. 2018;221:191-198. doi: 10.1016/j.ijheh.2017.10.012

3. Hajek P, Pittaccio K, Pesola F, et al. Nicotine delivery and users' reactions to Juul compared with cigarettes and other e-cigarette products. Addiction. 2020;115:1141-1148. doi: 10.1111/add.14936

4. Wagener TL, Floyd EL, Stepanov I, et al. Have combustible cigarettes met their match? The nicotine delivery profiles and harmful constituent exposures of second-generation and third-generation electronic cigarette users. Tob control. 2017;26:e23-e28. doi: 10.1136/tobaccocontrol-2016-053041

5. Herzog B, Kanada P. Nielsen: Tobacco all channel data thru 8/11 - cig vol decelerates. Published August 21, 2018. Accessed August 19, 2021. https://athra.org.au/wp-content/uploads/2018/09/ Wells-Fargo-Nielsen-Tobacco-All-Channel-Report-PeriodEnding-8.11.18.pdf

6. Harrell MB, Weaver SR, Loukas A, et al. Flavored e-cigarette use: characterizing youth, young adult, and adult users. Prev Med Rep. 2017;5:33-40. doi: 10.1016/j.pmedr.2016.11.001

7. Morean ME, Butler ER, Bold KW, et al. Preferring more e-cigarette flavors is associated with e-cigarette use frequency among adolescents but not adults. PloS One. 2018;13:e189015. doi: 10.1371/ journal.pone.0189015

8. Obisesan $\mathrm{OH}$, Osei $\mathrm{AD}$, Iftekhar Uddin $\mathrm{SM}$, et al. Trends in e-cigarette use in adults in the United States, 2016-2018. JAMA Intern Med. 2020;180:1394-1398. doi: 10.1001/ jamainternmed.2020.2817

9. Creamer MR, Wang TW, Babb S, et al. Tobacco product use and cessation indicators among adults-United States, 2018. MMWR Morb Mortal Wkly Rep. 2019;68:1013-1019. doi: 10.15585/mmwr. mm6845a2

10. NASEM. Public health consequences of e-cigarettes. National Academies Press; 2018. Accessed August 19, 2021. www.ncbi. nlm.nih.gov/books/NBK507171/

11. Hajek P, Phillips-Waller A, Przulj D, et al. A randomized trial of e-cigarettes versus nicotine-replacement therapy. $N$ Engl J Med. 2019;380:629-637. doi: 10.1056/NEJMoa1808779

12. Pulvers K, Nollen NL, Rice M, et al. Effect of pod e-cigarettes vs cigarettes on carcinogen exposure among African American and Latinx smokers: a randomized clinical trial. JAMA Netw Open. 2020;3:e2026324. doi: 10.1001/jamanetworkopen.2020.26324

13. Wang RJ, Bhadriraju S, Glantz SA. E-cigarette use and adult cigarette smoking cessation: a meta-analysis. Am J Public Health. 2021;111:230-246. doi: 10.2105/AJPH.2020.305999

14. Barrington-Trimis JL, Urman R, Berhane K, et al. E-cigarettes and future cigarette use. Pediatrics. 2016;138:e20160379. doi: 10.1542/ peds.2016-0379

15. Soneji S, Barrington-Trimis JL, Wills TA, et al. Association between initial use of e-cigarettes and subsequent cigarette smoking among adolescents and young adults: a systematic review and meta-analysis. JAMA Pediatr. 2017;171:788-797. doi: 10.1001/jamapediatrics.2017.1488

16. Krishnasamy VP, Hallowell BD, Ko JY, et al. Update: characteristics of a nationwide outbreak of e-cigarette, or vaping, product use-associated lung injury-United States, August 2019-Janu- ary 2020. MMWR Morb Mortal Wkly Rep. 2020;69:90-94. doi: 10.15585/mmwr.mm6903e2

17. Blount BC, Karwowski MP, Shields PG, et al. Vitamin E acetate in bronchoalveolar-lavage fluid associated with EVALI. $N$ Engl JMed. 2020;382:697-705. doi: 10.1056/NEJMoa1916433

18. CDC. Outbreak of lung injury associated with use of e-cigarette, or vaping, products. Updated February 25, 2020. Accessed August 19, 2021. www.cdc.gov/tobacco /basic_information/e-cigarettes/severe-lung-disease.html

19. American Psychiatric Association. Diagnostic and Statistical Manual of Mental Disorders. 5th edition (DSM-5). American Psychiatric Publishing; 2013.

20. CDC. International Classification of Diseases, 10th Revision. Updated July 30, 2021. Accessed August 31, 2021. www.cdc.gov/ nchs/icd/icdlocm.htm

21. CDC. Surgeon General's advisory on e-cigarette use among youth. Reviewed April 9, 2019. Accessed August 19, 2021. www. cdc.gov/tobacco/basic_information/e-cigarettes/surgeongeneral-advisory/index.html

22. Knight JR, Sherritt L, Shrier LA, et al. Validity of the CRAFFT substance abuse screening test among adolescent clinic patients. Arch Pediatr Adolesc Med. 2002;156:607-614. doi: 10.1001/ archpedi.156.6.607

23. DiFranza JR, Savageau JA, Fletcher K, et al. Measuring the loss of autonomy over nicotine use in adolescents: the DANDY (Development and Assessment of Nicotine Dependence in Youths) study. Arch Pediatr Adolesc Med. 2002;156:397-403. doi: 10.1001/archpedi.156.4.397

24. Wellman RJ, Savageau JA, Godiwala S, et al. A comparison of the Hooked on Nicotine Checklist and the Fagerström Test for Nicotine Dependence in adult smokers. Nicotine Tob Res. 2006;8:575-580. doi: 10.1080/14622200600789965

25. Fiore MC, Jaén CR, Baker TB, et al. Treating tobacco use and dependence: 2008 update. Published May 2008 Accessed August 19, 2021. www.aafp.org/dam/AAFP/ documents/patient_care/clinical_recommendations/ TreatingTobaccoUseandDependence-2008Update.pdf

26. Shah SD, Wilken LA, Winkler SR, et al. Systematic review and meta-analysis of combination therapy for smoking cessation. $\mathrm{J} \mathrm{Am}$ Pharm Assoc. 2008;48:659-665. doi: 10.1331/JAPhA.2008.07063

27. Vidrine JI, Shete S, Cao Y, et al. Ask-Advise-Connect: a new approach to smoking treatment delivery in health care settings. JAMA Intern Med. 2013;173:458-464. doi: 10.1001/ jamainternmed.2013.3751

28. Bentz CJ, Bayley KB, Bonin KE, et al. The feasibility of connecting physician offices to a state-level tobacco quit line. Am J Prev Med. 2006;30:31-37. doi: 10.1016/j.amepre.2005.08.043

29. Borland R, Segan CJ. The potential of quitlines to increase smoking cessation. Drug Alcohol Rev. 2006;25:73-78. doi: 10.1080/09595230500459537

30. Farber HJ, Walley SC, Groner JA, et al. Clinical practice policy to protect children from tobacco, nicotine, and tobacco smoke. Pediatrics. 2015;136:1008-1017. doi: 10.1542/peds.2015-3108

31. Gentzke AS, Wang TW, Jamal A, et al. Tobacco product use among middle and high school students-United States, 2020. MMWR Morb Mortal Wkly Rep. 2020;69:1881-1888. doi: 10.15585/mmwr. mm6950al

32. AAP. Nicotine replacement therapy and adolescent patients: information for pediatricians. Updated November 2019. Accessed August 19, 2021. https://downloads.aap.org/RCE/ NRT_and_Adolescents_Pediatrician_Guidance_factsheet.pdf

33. Blasi PR, Cromp D, McDonald S, et al. Approaches to behavioral health integration at high performing primary care practices. J Am Board Fam Med. 2018;31:691-701. doi: 10.3122/ jabfm.2018.05.170468

34. Jacobs C, Brieler JA, Salas J, et al. Integrated behavioral health care in family medicine residencies a CERA survey. Fam Med. 2018;50:380-384. doi: 10.22454/FamMed.2018.639260

35. Oliverez M. Quick guide: billing for smoking cessation services. Capture Billing. Accessed August 26, 2021. https://capturebilling. com/how-bill-smoking-cessation-counseling-99406-99407/ 